\title{
PEMAHAMAN KARYAWAN BTM AT-TAQWA TERHADAP TARJIH MUHAMMADIYAH ASPEK IBADAH
}

\section{UNDERSTANDING OF BTM AT-TAQWA EMPLOYEES TOWARDS MUHAMMADIYAH'S TARJIH ASPECT OF WORSHIP}

\author{
Syamsurizal $^{1)^{*}}$, Rosdialena $^{2)}$, Yoni Marlius ${ }^{3)}$ \\ ${ }^{1,2.3)}$ Universitas Muhammadiyah Sumatera Barat, Padang, Indonesia \\ syaasy1284@yahoo.com
}

\begin{abstract}
ABSTRAK: Penelitian ini bertujuan untuk mengungkapkan bagaimana pemahaman karyawan BTM at-Taqwa terhadap hasil putusan tarjih Muhammadiyah khususnya dalam aspek ibadah, hal ini penting untuk dilakukan mengingat semua sumber daya manusia yang bekerja pada amal usaha Muhammadiyah dituntut agar mengamalkan ajaran Islam terutama yang sesuai dengan keputusan hasil tarjih Muhammadiyah. Penelitian dilakukan di BTM at-Taqwa Muhammadiyah Kota Padang, pendekatan yang digunakan ialah kualitatif, teknik pengumpulan data menggunakan observasi, wawancara dan dokumentasi. Hasil penelitian ini membuktikan bahwa karyawan BTM at-Taqwa Muhammadiyah belum memiliki pemahaman yang kuat terhadap putusan tarjih Muhammadiyah khususnya pada aspek ibadah, kesimpulan ini didasarkan pada rendahnya pengamalan karyawan BTM at-Taqwa terhadap shalat yang sesuai dengan hasil putusan tarjih. Penyebab rendahnya pemahaman karyawan terhadap pemahaman tarjih disebabkan oleh minimnya pembinaan yang berbentuk kajian, tidak ada regulasi yang mendukung secara tertulis, tidak adanya control pimpinan, dan belum adanya training kader seperti baitul Arqam, dan Darul Arqam.
\end{abstract}

Kata Kunci: Tarjih, ibadah, pemahaman

ABSTRACT: This study aims to reveal how the understanding of BTM at-Taqwa employees to the results of muhammadiyah tarjih verdicts, especially in the aspect of worship, is important to do considering all human resources working in muhammadiyah business charities are required to practice Islamic teachings, especially those in accordance with the decision of muhammadiyah tarjih results. The research was conducted at BTM at-Taqwa Muhammadiyah Padang City, the approach used is qualitative, data collection techniques using observation, interview and documentation. The results of this study prove that btm at-Taqwa Muhammadiyah employees do not have a strong understanding of the verdict of Tarjih Muhammadiyah, especially in the aspect of worship, this conclusion is based on the low practice of BTM at-Taqwa employees to pray in accordance with the results of tarjih verdicts. The cause of the low understanding of employees to the understanding of tarjih is due to the lack of coaching in the form of studies, no regulations that support in writing, the absence of leadership control, and the absence of cadre training such as baitul Arqam, and Darul Arqam.

Keywords: Tarjih, worship, understanding

\section{A. PENDAHULUAN}

Pertumbuhan amal usaha muhammadiyah yang telah memiliki aset ribuan Amal Usaha yang tersebar di atas tanah lebih kurang 21 Juta meter persegi (Damanuri, 2012) di seluruh pelosok dunia, dan setiap amal usaha yang dimiliki oleh Muhammadiyah baik dalam bentuk lembaga pendidikan, lembaga kesehatan, lembaga keuangan serta lembaga lainnya memiliki banyak karyawan (Mursal et al., 2021). Keberadaan karyawan pada amal usaha Muhammadiyah bukan hanya diperuntukan pemenuhan job kerja yang membutuhkan sumber daya manusia, melainkan turut serta mengembangkan amal usaha Muhammadiyah (Purba \& Ponirin, 2013). 
Pengembangan amal usaha Muhammadiyah yang dimaksud seutuhnya bukan hanya sebatas pengembangan fisik, melainkan teraktualisasinya ideology dan pemahaman yang disepakati dalam Muhammadiyah pada amal usaha (Fikar et al., 2019). Untuk membumikan pemikiran dan ideology Muhammadiyah pada setiap amal usaha tidak bisa dipisahkan dengan pengamalan nyata dalam kehidupan sehari-hari tentang setiap yang telah menjadi kesepakatan dalam Muhammadiyah (Subarkah, 2017).

Di antara kesepakatan yang mesti diamalkan setiap sumber daya manusia yang menyatakan diri sebagai anggota Muhamamdiyah atau karyawan pada amal usaha Muhammadiyah ialah Himpunan Putusan Tarjih Muhammadiyah (Anwar, 2018). Di dalam Himpunan Putusan Tarjih ditemukan dalil yang jelas tentang bagaimana seorang muslim berperilaku, beribadah (Muhammadiyah, 2013), beraqidah dan bermu'amalah sesuai dengan ajaran Islam yang sebenarnya (Sulanam, 2019). Sebagai hasil kajian yang mendalam dari para ulama Muhammadiyah (Ritonga et al., 2020), Himpunan Putusan Tarjih dan Tajdid seharusnya tidak hanya untuk dokumen yang disimpan secara rapi (Samsuri \& Hayati, 2006), melainkan disosialisasikan, diaktualisasikan dan diamalkan dalam kehidupan sehari-hari.

Sejalan dengan itu, aspek ibadah merupakan bagian ajaran Islam yang menjadi objek Tarjih dan Tajdid para ulama Muhammadiyah (Rachmadhani, 2020). Shalat yang menjadi objek kajian tarjih termasuk bacaan dalam shalat, tata cara pelaksanaan shalat dalam kondisi tertentu, gerakan shalat, serta shalat-shalat sunnah. Terkait dengan putusan tarjih yang semestinya tidak hanya untuk didokumentasikan dalam bentuk buku Himpunan Putusan Tarjih (Muhammadiyah, 2013), melainkan diamalkan oleh seluruh warga Muhammadiyah dan Aisyiyah.

Tuntutan untuk mengamalkan putusan tarjih dan tajdid Muhammadiyah ialah dikarenakan hasil tarjih tersebut merupakan identitas dan cirri warga Muhammadiyah. Dan perlu diketahui bahwa, untuk dapat mengamalkan sesuatu tidak terlepas dari bagaimana tingkat pemahaman terhadap sesuatu yang semestinya diamalkan. Artinya di sini adalah warga Muhammadiyah dimana saja tidak akan mungkin dapat mengamalkan putusan tarjih tanpa adanya pemahaman terhadap isi putusan tarjih yang dimaksudkan.

Hasil bacaan terhadap berbagai literature yang terkait dengan pemahaman terhadap putusan tarjih menununjukkan masih banyak di antara warga Muhammadiyah yang tidak memahami secara baik tentang putusan tarjih (Amalia, 2019), (Ediz \& Bus, 2020). Realita yang sama juga peneliti temukan pada saat melaksanakan observasi awal terhadap cara beribadah karyawan di BTM atTaqwa Muhammadiyah Kota Padang, ternyata wawasan fikih karyawannya masih belum mencapai pemahaman fikih yang sejalan dengan wawasan fikih tarjih Muhammadiyah. Padahal paham ketarjihan itu merupakan identitas dan ciri khas Muhammadiyah sebagai pembeda dengan yang lain. Penelitian ini menjadi penting mengingat usia Muhammadiyah sudah memasuki abad kedua, kondisi ini belum mendapat perhatian serius oleh Pimpinan persyarikatan. Faktanya bahwa amal usaha Muhammadiyah adalah wadah kader Muhammadiyah, misalanya sekolah, universitas, panti Asuhan, rumah sakit, BTM, klinik dan lain-lain untuk membesarkan Muhammadiyah sebagai persyarikatan (Lelisari, 2020).

Hingga saat ini belum semua karyawan amal usaha muhammadiyah memiliki pemahaman fikih sejalan dengan wawasan fikih tarjih (Ini mengindikasikan bahwa Muhammadiyah secara struktural belum proporsional dalam pembinaan masalah ini. Padahal ini segmen yang sangat krusial bagi pembentukan karakter kader Muhammadiyahsebagai pelopor pelangsung penyempurna amal usaha Muhammadiyah.

Amal Usaha Muhammadiyah merupakan komunitas wadah dakwah bagi persyarikatan, maka karyawan amal usaha merupakan bahagian dari komunitas da'i Muhammadiyah. BTM At Taqwa Muhammadiyah adalah salahsatu Amal usaha yang memiliki tanggungjawab mengembangkan dakwah amar ma'ruf nahi mungkar sesuai fokus dakwah Muhammadiyah. Karyawan Amal usaha merupakan da'i persyarikatan Muhammadiyah. 
Penelitian ini bertujuan untuk mengetahui secara signifikan bagaimana wawasan fikih karyawan BTM At Taqwa Muhammadiyah Padang. Indikasi dalam penelitian ini adalah kurangnya wawasan fikih karyawan BTM At Taqwa Muhammadiyah yang belum sesuai dengan faham ketarjihan Muhammadiyah (HPT). Buku HPT merupakan pedoman praktis bagi warga Muhammadiyah dalam pelaksanaan ibadah. Dengan mempedomani buku ini karyawan BMT At Taqwa bisa memperoleh pemahaman secara cepat dan praktis.i Target luaran penelitian ini hasil berupa artikel ilmiah tentang wawasan fikih karyawan BTM At Taqwa Muhammadiyah Padang dalam perspektif tarjih.

\section{B. METODE PENELITIAN}

Penelitian ini menggunakan pendekatan kualitatif, pendekatan ini digunakan karena data yang ingin ditemukan dan dianalisis ialah berupa fakta yang tidak mungkin diuraikan secara statistik. Adapun tempat penelitian ini ialah bertempat di kantor pusat BTM at-Taqwa Muhammadiyah Padang. Tempat ini dipilih karena merupakan pusat BTM yang seharusnya menjadi acuan dan rujukan bagi BTM lain dalam hal pengamalan nilai-nilai Islam tanpa terkecuali pengamalan putusan tarjih dalam beribadah.

Lokasi penelitian ini dapat dilihat sebagaimana pada gambar di bawah ini yang diambil dari google map.

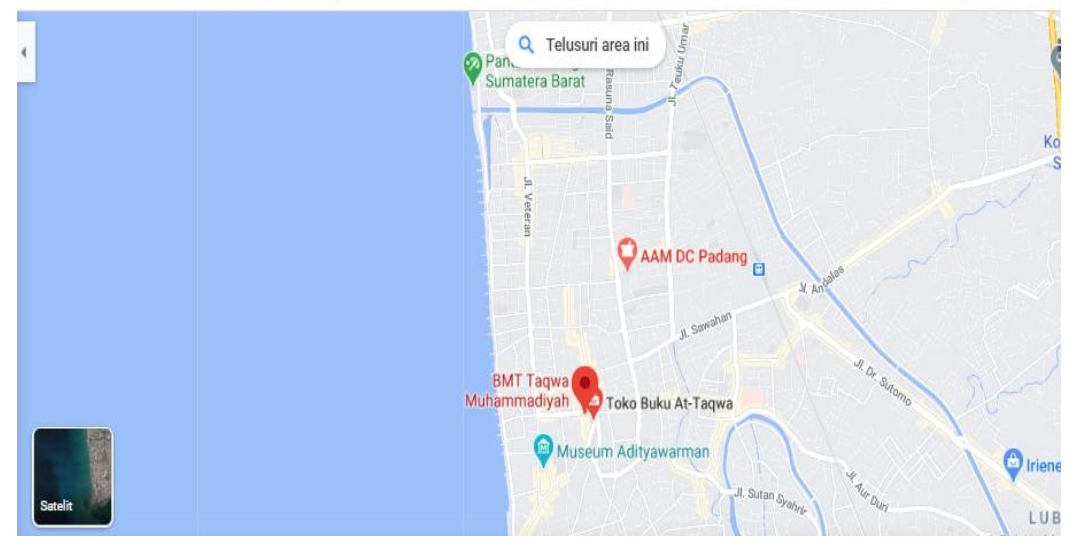

Gambar 1. Lokasi Penelitian

Penelitian ini berlangsung pada bulan Mei sampai Desember 2020, sejalan dengan pemilihan tajuk tersebut studi ini mengunakan jenis penelitian kualitatif deskriptif untuk memahami fenomena sosial sesuai perspektif informan. Dalam pelaksanaanya dilakukan kunjungan ke kantor Pusat BTM at-Taqwa Padang sebanyak 4 kali. Di lokasi dilakukan pengamatan terhadap aktivitas dan kegiatan karyawan, kemudian dilanjutkan dengan menginterviev informan diantaranya manager, kepala bagian keuangan, pengawas, teller dan lainnya.

\section{HASIL DAN PEMBAHASAN}

BTM at-Taqwa Muhammadiyah pada awalnya bernama BMT Taqwa Muhammadiyah, amal usaha ini letaknya di Masjid Taqwa Muhammadiyah Pasar Pasar Raya Padang. Secara historis, amal usaha ini berdiri pada tanggal 9 September 1996. BTM at-Taqwa yang awalnya BMT Muhammadiyah berdiri dengan modal yang pas-pasan yakni 2.701.000,- (Dokumentasi, 2020). Data ini sesuai dengan pernyataan manager yang menegaskan bahwa awal berdirinya BTM ini yang dulunya BMT tidak disangka akan menjadi sebesar saat sekarang (Manager BTM, Wawancara, 2020). 
Dari data yang ditemukan, diketahui bahwa fungsi dan peran BTM at-Taqwa ialah pertama, mengembangkan potensi dan kemampuan ekonomi masyarakat terlebih khusus anggota, kedua, berperan aktif dalam upaya meningkatkan kualitas hidup masyarakat, ketiga memperkokoh perekonomian rakyat sebagai dasar kekuatan dan ketahanan perekonomian nasional dengan koperasi soko-gurunya, keempat, mengembangkan perekonomian nasional, dengan usaha bersama berdasarkann azas kekeluargaan dan demokrasi ekonomi (Dokumentasi, 2020).

Sebagai bagian dari amal usaha Muhammadiyah, BTM at-Taqwa menerapkan segala kebijakan yang dikeluarkan oleh pimpinan pusat Muhammadiyah tanpa terkecuali pengamalan keputusan tarjih Muhammadiyah (Manager BTM, Wawancara, 2020). Namun demikian, disebabkan karyawan yang memiliki kesibukan dalam pengelolaan BTM atTaqwa Muhammadiyah, terkadang apa yang telah menjadi keputusan pimpinan baik daerah maupun pusat tidak terekam oleh semua anggota (Manager BTM, Wawancara,, 2020).

Dampak yang terlihat dalam hal ini ialah banyak di antara karyawan BTM terkesan hanya bekerja di Muhammadiyah tetapi tidak mengamalkan jati diri Muhammadiyah dalam kehidupan (Observasi, 2020). Pernyataan ini didasarkan pada masih terdapatnya karyawan yang tidak menutup secara langsung kantor ketika waktu shalat sudah tiba (Observasi, 2020), karyawan yang masih merokok (Observasi, 2020) padahal rokok telah diharamkan sebagaimana dalam putusan tarjih Muhammadiyah.

Hasil yang dicapai dalam penelitian yang dilaksanakan pada bulan Mei sampai Desember 2020 di kantor Pusat BTM At Taqwa Muhammadiyah adalah diketahui indikasi bahwa wawasan fikih karyawan BTM At Taqwa Muhammadiyah masih rendah dan belum sesuai dengan tuntunan himpunan putusan tarjih Muhammmadiyah.

Berdasarkan hasil wawancara dengan karyawan kantor Pusat BTM At Taqwa Muhammadiyah Padang diperoleh keterangan tentang wawasan fikih masing-masing individu. bahwa wawasan fikih mereka belum sepenuhnya sesuai dengan wawasan fikih Muhammadiyah berdasarkan tuntunan manhaj tarjih. Rendahnya wawasan fikih ini diduga belum makasimalnya pembinaan Muhammadiyah secara terstrutktur dan kontiniu. Dari jawaban peserta wawancara ada beberapa faktor-faktor yang menjadi penyebab, diantaranya:

1. Latar belakang pendidikan karyawan Kantor Pusat BTM At Taqwa Muhammadiyah mayoritas bukan pendidikan agama melainkan sebagian kecil saja lulusan Jalur Pendidikan Agama. Kondisi ini mengindikasikan sedikitnya bahkan boleh jadi tidak adanya pembalajaran fikih di lembaga tempat mereka belajar.

2. Sebagian besar karyawan Kantor Pusat BTM At Taqwa Muhammadiyah belum mendapat pembinaan dan pembelajaran fikih Muhammadiyah baik sebelum menjadi karyawan maupun setelah menjadi karyawan BTM At Taqwa Muhammadiyah.

3. BMT At Taqwa belum fokus memberikan pembinaan ke Islaman khususnya di bidang fikih.

4. Karyawan Kantor Pusat BTM At Taqwa hampir semuanya mengakui belum mengetahui wawasan fikihnya belum sesuai tuntunan Himpunan Putusan Tarjih Muhammadiyah.

5. Ada sebagian yang mengakui bahwa ia sudah mengenal fikih Tarjih Muhammadiyah saat Aktif di Organisasi Ikatan Mahasiswa Muhammadiyah.

6. Semua karyawan Kantor Pusat BTM At Taqwa Muhammadiyah mengakui bahwa pembinaan secara resmi tentang fikih sesuai Himpunan Putusan Tarjih Muhammadiyah sangat minim. Mereka menuturkan baru satu kali dalam kegiatan Baitul Arqam Dasar Muhammadiyah.

Berdasarkan data yang dijelaskan di atas dapat diungkapkan bahwa karyawan BTM atTaqwa Muhammadiyah memiliki pemahaman yang rendah dalam masalah yang terkait 
dengan putusan tarjih Muhamamdiyah dalam aspek ibadah. Indikator yang mendasari pernyataan ini ialah dapat dilihat dalam table 1 di bawah ini:

Table 1. Pemahaman Karyawan terhadap Ibadah Shalat

\begin{tabular}{|c|c|c|}
\hline No & Aspek & Temuan \\
\hline 1 & Bacaan Shalat & $\begin{array}{l}\text { - Terdapat karyawan } \\
\text { membaca iftitah }\end{array}$ \\
\hline & & $\begin{array}{l}\text { - Terdapat karyawan } \\
\text { basmalah zahar }\end{array}$ \\
\hline 2 & Gerakan shalat & $\begin{array}{l}\text { - } \text { Gerakan belum sesuai Tarjih } \\
\text { - Takbiratul ihram belum sesuai tarjih } \\
\text { - Duduk tasyahud akhir belum sesuai } \\
\text { tarjih }\end{array}$ \\
\hline
\end{tabular}

Data yang terdapat pada table 1 di atas membuktikan bahwa karyawan BTM at-Taqwa belum sepenuhnya memahami putusan tarjih terkait dengan ibadah shalat. Ibadah shalat merupakan rukun Islam, jadi setiap orang mukallaf mesti mendirikan shalat, dalam hal ini Muhammadiyah telah memiliki jati diri berdasarkan kajian para ulama yang kemudian dituangkan dalam Himpunan Putusan Tarjih bagaimana cara melaksanakan shalat serta bacaan yang mesti dibaca pada saat shalat, artinya ketika hal itu tidak dilakukan ketika shalat maka identitas kemuhammadiyahannya belum dapat diakui secara ideology.

Sementara itu, ketika dikonfirmasi terhadap karyawan yang bersangkuta didapatkan jawaban bahwa dia tidak berlatarbelakang pendidikan berbasis Islam (Karyawan, Wawancara, 2020). Informan lain juga mengungkapkan bahwa karyawan BTM at-Taqwa tidak sepenuhnya berlatarbelakang lembaga pendidikan keislaman (Informan, Wawancara, 2020). Pernyataan kedua informan ini mengindikasikan bahwa BTM at-Taqwa tidak melakukan pendidikan kader Muhammadiyah seutuhnya pada amal usaha Muhammadiyah, padahal seyogiyanya setiap amall usaha Muhammadiyah harus menjadi pusat kaderisasi dan penanaman nilai-nilai keislaman dan kemuhammadiyahan (Hakim et al., 2020).

Di sini juga membuktikan bahwa karyawan BTM at-Taqwa belum memiliki niat yang utuh dan komitmen yang kuat untuk mengamalkan ajaran Islam yang sesuai dengan al-Quran dan Sunnah. Dikatakan demikian ialah karena putusan tarjih Muhammadiyah merupakan kajian yang mendalam tentang dalil-dalil yang paling otoritatif digunakan untuk menetapkan sebuah hukum (Sulaiman, 2012). Artinya di sini ialah bahwa warga Muhammadiyah tidak semestinya meragukan isi yang dituangkan dalam Himpunan Putusan Tarjih Muhammadiyah karena sudah melalui kajian yang mendalam dari para ulama yang dianggap memiliki otoritas dalam menetapkan hukum.

Alasan tidak berlatarbelakang pendidikan yang berbasis keislaman tidak semestinya dilontarkan oleh warga Muhammadiyah apalagi yang bekerja dan mengabdikan diri pada amal usaha Muhammadiyah ditambah lagi dalam masalah yang terkait dengan shalat. Shalat bagi seorang muslim merupakan fardhu 'ain, oleh karenanya setiap orang memiliki kewajiban untuk mempelajari agar tidak ragu dalam melaksanakan shalat (Istianah, 2015), (Iswari et al., 2020). Selain itu, pihak BTM at-Taqwa seharusnya memberikan pendidikan kepada seluruh karyawan terkait dengan putusan tarjih.

Pemahaman terkait dengan ibadah shalat juga dapat dilakukan dengan memperbanyak bacaan terhadap karya-karya para ulama, dan jika ingin pemahamannya sesuai dengan apa yang telah diputuskan dalam Himpunan Putusan tarjih Muhammadiyah maka karya-karya ulama Muhammadiyah bisa dijadikan sebagai sumber bacaan (Ritonga et al., 2021). Shalat sebagaimana yang telah diatur dalam putusan Tarjih Muhammadiyah seharusnya dilaksanakan dengan:

Pertama, niat semata-mata karena Allah. Setiap muslim dilarang mendirikan shalat tanpa disertai dengan niat yang tulus karena Allah, karena tidak ada yang pantas disembah, dipuji, dibesarkan serta diagungkan selain Allah. Niat yang terletak dalam hati tidak akan mungkin dapat diketahui oleh masyarakat banyak, yang mengetahuinya hanyalah Allah dan individu masing- 
masing, para ulama sepakat bahwa segala amal yang dikerjakan tanpa didasarkan pada niat yang ikhlas karena Allah tidak akan syah (Syamhudi, 2014).

Pada aspek niat, pemahaman karyawan BTM at-Taqwa masih banyak dipengaruhi oleh sumber yang tidak kuat dalilnya, di antara mereka ada yang beranggapan bahwa niat dalam shalat itu ialah selalu menggunakan kalimat Ushalli, seperti yang diungkapkan oleh salah seorang informan yang menyatakan bahwa niat shalat itu ketika mengucapkan ushalli (Informan, Wawancara, 2020). Pemahaman yang lemah dari karyawan pada aspek niat terlihat ketidakmengertian mereka dengan niat yang sesungguhnya adalah shalat semata-mata karena Allah. Sementara penggunaan kalimat Ushalli tidak termasuk niat (Ilyas \& Harahap, 2019).

Kedua, Menghadap kiblat. Sesuai dengan yang diputuskan dalam himpunan putusan tarjih muhammadiyah diketahui bahwa pelaksanaan shalat mesti menghadap kiblat (Sopa, 2016). Dalam hal ini, karyawan BTM at-Taqwa Muhammadiyah tidak memahami keharusan menghadap kiblat, sesuai dengan yang diungkapkan oleh informan bagi mereka arah masjid/mushalla sudah menjadi acuan baku dalam mendirikan shalat (Informan, Wawancara, 2020). Sementara dalam Islam diharuskan agar setiap umat tidak taklid buta dalam kehidupan terutama dalam masalah agama (Syahriar \& Mubarok, 2018).

Ketiga, berdiri tegak, dalam putusan tarjih Muhammadiyah ditegaskan bahwa shalat mesti dilaksanakan secara berdiri tegak bagi yang mampu, jika tidak mampu boleh dilaksanakan secara duduk dan jika tidak mampu bisa dilaksanakan dengan berbaring. Pemahaman karyawan BTM atTaqwa Muhammadiyah dalam aspek ini terlihat sangat lemah. Seorang informan menyatakan bahwa sesuai dengan yang dia pahami shalat tidak bisa dilakukan selain berdiri (Informan, Wawancara, 2020). Pernyataan ini menunjukkan bahwa keputusan yang dituangkan dalam Himpunan Putusan Tarjih Muhammadiyah tidak dipahami secara baik. Berdasarkan data di atas dapat ditegaskan bahwa putusan tarjih tentang shalat tidak dipahami secara baik oleh karyawan BTM at-Taqwa, karena aspek-aspek yang terkait dengan shalat telah dijelaskan dalam HPT dan disertai dengan dalil-dalil yang dipandang lebih kuat (Poniman, 2016).

Sesuai dengan data yang dijelaskan di atas serta dibahas dengan hasil penelitian para pemerhati putusan tarjih Muhammadiyah dapat dipahami bahwa Himpunan Putusan Tarjih belum tersosialisasi secara menyeluruh kepada semua warga Muhammadiyah tanpa terkecuali warga muhammadiyah yang bekerja pada amal usaha Muhammadiyah seperti BTM a-Taqwa Muhammadiyah. Realita ini tidak tertutup kemungkinan terjadi pada warga Muhammadiyah yang bekerja pada amal usaha Muhammadiyah yang lain, seperti guruguru pada sekolah Muhammadiyah, tenaga kependidikan, tenaga kesehatan pada rumah sakit, pegawai rumah sakit, dosen pada universitas serta tenaga kependidikan serta warga Muhammadiyah pada amal usaha yang lain.

Karyawan, pegawai, tenaga kesehatan, guru, dosen dan setiap yang mengabdikan diri pada amal usaha muhammadiyah seharusnya memahami secara baik hal-hal yang terkait dengan jati diri Muhammadiyah. Pandangan ini sejalan dengan kesimpulan yang dijelaskan oleh Fikar dan kawankawan bahwa sumber daya manusia yang belum memahami pandangan hidup dan jati diri muhammadiyah perlu dilakukan pembinaan guna meningkatkan pemahaman dan pengamalan mereka terhadap Islam yang sesuai dengan al-Quran dan Sunnah (Fikar et al., 2019). Dikatakan demikian karena setiap orang yang bekerja pada amal usaha muhammadiyah selayaknya menjadi actor yang turut membesarkan Muhammadiyah melalui pengamalan Al-Islam dan Kemuhammadiyahan.

\section{PENUTUP}

Setelah melakukan analisis dan membahas hasil penelitian sebagaimana yang telah diuraikan di atas dapat ditarik kesimpulan bahwa pemahaman karyawan BTM at-Taqwa terhadap putusan tarjih Muhamamdiyah dalam aspek shalat masih rendah, hal ini dapat ditegaskan karena melihat gerakan dan bacaan beberapa karyawan yang belum sesuai dengan keputusan tarjih. Sejalan dengan temuan ini, pihak BTM at-Taqwa sudah seharusnya 
memberikan sosialisasi atau bentuk kajian yang mengarah pada peneingkatan pengamalan alislam dan kemuhammadiyahan bagi seluruh karyawan. Karyawan dan setiap orang yang mengabdikan diri pada amal usaha muhammadiyah sudah seharusnya menjadi pelopor dan actor dalam mengamalkan ajaran Islam terutama yang sesuai dengan al-Quran dan Sunnah.

\section{E. UCAPAN TERIMAKASIH}

Peneliti mengucapkan terimakasih yang sebesar-besarnya kepada Rektor Universitas Muhammadiyah Sumatera Barat yang telah memberikan pendanaan kepada LPPM untuk mengadakan hibah internal. Terimakasih juga kepada ketua LPPM dan team yang telah melakukan seleksi terhadap semua proposal yang masuk sehingga kami diberikan kesempatan untuk mendapatkan pendanaan yang dimaksud. Tidak luput juga kepada Bapak Dekan Fakultas Agama Islam yang telah memberikan kesempatan bagi dosen FAI untuk berkontribusi dalam penelitian yang didanai oleh LPPM. Terimakasih yang sepenuhnya kami ucapkan kepada Direktur PPs UM Sumbar yang senantiasa memberikan pencerahan dan motivasi untuk senantiasa mengembangkan research dan publikasi.

\section{F. DAFTAR PUSTAKA}

Amalia, H. (2019). Muhammadiyah: Metode dan Praktek Berijtihad. MUADDIB: Studi Kependidikan Dan Keislaman, 09(02), 119-130.

Anwar, S. (2018). Manhaj Tarjih Muhammadiyah. Tajdida, 16(1), 1-3. http://journals.ums.ac.id/index.php/tajdida/article/view/7606/4349

Damanuri, A. (2012). Efektivitas dan Efisiensi Pemanfaatan Harta Wakaf Majlis Wakaf Pimpinan Daerah Muhammadiyah ponorogo. Kodifikasi, 6(1), 77-98.

Ediz, M. H., \& Bus, Y. (2020). Majelis Tarjih dan Tajdid Sebagai Pemegang Otoritas Fatwa Muhammadiyah. Journal Al-Ahkam, XXI(1), 149-168.

Fikar, M., Ritonga, M., \& Mursal. (2019). Strategi Piminan Wilayah Muhammadiyah dalam Melakukan Perekrutan Guru di SMA Muhammadiyah Se Kota Padang. Ruhama: Islamic Education Journal, 2(2), 69-82.

Hakim, R., Khadijah, Ritonga, M., Susanti, W., \& Rahmi. (2020). Institute Quality Improvement Through Management Training of Accreditation Preparation in TK Aisyiyah Bustanul Athfal Padang. Advances in Social Science, Education and Humanities Research, Volume 449 Proceedings of the International Conference of Early Childhood Education (ICECE 2019), 44(Icece 2019), 55-65. https://doi.org/https://doi.org/10.2991/assehr.k.200715.012

Ilyas, A. F., \& Harahap, R. M. (2019). Polemik Ulama Nusantara: Narasi Faktual Tentang Kebebasan Berpendapat. Jrnal: Penelitian Medan Agama, 10(2), 174-195.

Istianah. (2015). Shalat Sebagai Perjalanan Ruhani Menuju Allah. ESOTERIK, 1(1), 4764.

Iswari, N., Mursal, \& Rahmi. (2020). Praying in The Subject of Practice of Worship in SMK Muhammadiyah 1 Padang. Ruhama: Islamic Education Journal, 3(1), 34-44.

Lelisari. (2020). Tanggung jawab sosial dan lingkungan badan usaha milik muhammadiyah (bumm) terhadap masyarakat dan lingkungan. Media Keadilan Jurnal Ilmu Hukum, 11(2), 293-307. https://doi.org/10.31764/jmk.v11i2.3084

Muhammadiyah, M. T. dan T. P. P. (2013). Tuntunan Ibadah pada Bulan Ramadhan (2 (ed.)). GRAMASURYA.

Mursal, M., Ritonga, M., Sartika, F., Lahmi, A., Nurdianto, T., \& Alam, L. (2021). The contribution of Amil Zakat, Infaq and Shadaqah Muhammadiyah ( LAZISMU ) institutions in handling the impact of Covid-19 The contribution of Amil Zakat, Infaq and Shadaqah. Journal of Sustainable Finance \& Investment, O(0), 1-7. 
https://doi.org/10.1080/20430795.2021.1886550

Poniman. (2016). Analisis tingkat pemahaman dan pengamalan tata cara shalat menurut himpunan putusan tarjih pada siswa mts muhammadiyah kabupaten bantul. Prosiding Interdisciplinary Postgraduate Student Conference 1st, 190-198.

Purba, I. A., \& Ponirin. (2013). Perkembangan Amal Usaha Organisasi Muhammadiyah di Bidang Pendidikan dan Kesehatan. Jurnal Ilmu Pemerintahan Dan Sosial Politik $U M A, 1(2), 101-111$.

Rachmadhani, F. (2020). Konsep Bid'ah Perspektif Muhammadiyah; Kajian Fatwa Majelis. Kalimah: Jurnal Studi Agama-Agama Dan Pemikiran Islam, 18(1), 77-102.

Ritonga, M., Bustami, H., Saputra, R., Hakim, R., Mursal, Elhusen, S. K., \& Marlius, Y. (2020). Reformulating the arabic language teaching materials within the framework of generating new cadres of Tarjih and Tajdid Ulama. International Journal of Advanced Science and Technology, 29(7), 185-190.

Ritonga, M., Widodo, H., Munirah, \& Nurdianto, T. (2021). Arabic language learning reconstruction as a response to strengthen Al-Islam studies at higher education. International Journal of Evaluation and Research in Education (IJERE), 10(1), 355363. https://doi.org/10.11591/ijere.v10i1.20747

Samsuri, \& Hayati, I. N. (2006). Kajian Tematis Keputusan-Keputusan majelis Tarjih Muhammadiyah tentang Perempuan. Millah, V(2), 243-259.

Sopa. (2016). Manhaj Tarjih Muhammadiyah dan Implementasinya dalam Hisab Arah Kiblat dan Waktu-Waktu Salat. Misykat Al-Anwar Jurnal Kajian Islam Dan Masyarakat., 27(1), 1-13. https://doi.org/10.31904/ma.v27i1.3820

Subarkah, M. A. (2017). Muhammadiyahdan amal usaha di bidang pendidikan. Rausyan Fikr, 13(2), 11-24.

Sulaiman, A. (2012). Metode tarjih muhammadiyah dalam menyeleksi hadist-hadist nabi sebagai sumber hukum syara'. Tajdid, 10(1), 67-85.

Sulanam. (2019). Rilis Putusan dan Produk Fatwa Majlis Tarjih Muhammadiyah. Yudisia: Jurnal Pemikiran Hukum Dan Hukum Islam, 10(1), 81-97.

Syahriar, A., \& Mubarok, A. F. (2018). Analisis Kritis Implementasi Taklid dalam Beraga Tinjauan Ushul Fiqh Empat Mazhab dan Pengaruhnya terhadap Nilai-Nilai Kebangsaan Negara Kesatuan Republik Indonesia (NKRI). Yudisia: Jurnal Pemikiran Hukum Dan Hukum Islam, 9(1), 101-120.

Syamhudi, A. 'Abbas K. (2014). Fikih Niat Peran Niat dalam Amal. In Niat. Maktabah Abu Salma. http://dear.to/abusalma 